\title{
iCollaborate or Not: Does Technology Impede Collaborative Learning among Primary Grade Students?
}

\author{
William R. Garris, Lindsay Lester, Erin Doran, Andrea Lowery and Amy \\ Weber \\ East Tennessee State University \\ USA
}

\begin{abstract}
The practice of education promotes both social interaction and the utilization of technology. Although significant research has explored the role of technology in education, less attention has considered the effect of technology on group learning processes. This experimental study examined the way in which technology affected group interactions among primary grades youth who were engaged in a learning task. The social processes in the learning groups that used technology showed little difference from the groups not using technology, except for a measure that tracked role fulfillment. The report compares the groups and discusses ICT mediated collaborative learning.
\end{abstract}

Keywords: education, collaborative learning, information and communication technology, social interactions.

\section{Introduction}

Our lives are affected by technology. Compared to a century ago, information and communication technology (ICT) is often a part of our work, deeply embedded in our personal space, and integrated with educational practice. As is often the case, the technology is invented, adopted, and only later researchers explore the impact. This has notably been the situation with the advent of radio, television, and video games, all of which had a slower adoption rate than the rapidly embraced personal ICT of today, such as smartphones (Ferguson, 2015; Bandura, Ross, \& Ross, 1963; Radesky, Schumacher, \& Zuckerman, 2015; Turkle, 2011). Personal technology, ICT in particular, is now ubiquitous, and the change has been rapid.

A review of research suggests technology may be disruptive to social relationships. This is significant in education because the classroom is a social 
space. Social constructivism holds that learning is mediated through dialogue. Further, a great deal of socialization occurs within the classroom.

However, in addition to being a social space, the classroom is also a sphere which has been deeply penetrated by technology. Technology is present for good reason. A wealth of studies supports the role of technology in student achievement. However, research has not generally considered the implications of technology on the social interactions that are also a part of learning and student development.

This study reviews other work that considers the effect of technology on relationships, primarily adult relationships. It examines the social nature of the classroom and collaborative learning in particular. Finally, the study reports the results of and implications from a study that examined the influence of technology on collaborative learning.

\section{Technology and Relationships}

Technology: Ubiquitous and Socially Disruptive. In 1986, professor and historian of technology Melvin Kranzberg penned "Kranzberg's Laws," six truisms about technology. Kranzberg's First Law reads thus: "Technology is neither good nor bad; nor is it neutral" (Kranzberg, 1986, p. 545). It may not be inherently good or bad, but it is doing something. Walk through any public space and it is likely that you will see people, maybe a majority, using some sort of electronic device. The Pew Research Center found that $94 \%$ of young adults in the United States owned a smartphone. One hundred percent had a cellphone, and over half of all households also had a tablet (Pew Research Center, 2018). In addition, most college students indicated that they are overly dependent on their phones (Emmanuel, et al., 2015). Personal technology is ubiquitous. It is also not neutral.

This technology has benefits, but also consequences. As one illustration, an early study of undergraduates, measured with the Internet Addiction Scale, found a relationship between high Internet usage and diminished emotional and social skills. This same study identified a relationship between excessive time on the Internet and loneliness (Engelberg \& Sjoberg, 2004). Subsequent research has identified correlations between Internet addiction and depression and anxiety issues, notably social phobia (Kuss \& Lopez-Fernandez, 2016; Liang, Zhou, Yuan, Shao, \& Bian, 2016; Malak \& Kahlifeh, 2018; Yayan, Arikan, Saban, Gürarslan Baş, \& Özel Özcan, 2017).

Mere presence. Communication technology was generally intended to connect people; however, research noted the mere presence of smartphones could impede face-to-face relationships. For example, Przyblyski and Weinstein (2013) conducted two experiments wherein a smartphone was present while people conversed. The first experiment randomly assigned 74 participants to either a phone-absent or phone-present condition. In the phone present condition, a phone was left on a nearby table, but outside participants' direct field of view, while they engaged in a prescribed, standardized relationship task for ten 
minutes. Results from a number of relationship measures indicated the unobtrusive presence of a smartphone negatively affected relationship quality and partner closeness.

Przyblyski and Weinstein's (2013) second experiment used a 2x2 design and contrasted phone-absent and phone-present conditions upon either casual or meaningful conversations. Interestingly, a present phone had no effect when the conversation was casual. However, having a phone present predicted lowered relationship quality, perceived empathy, and partner trust when involved in meaningful conversation. A field experiment (Misra, Cheng, Genevie \& Yuan, 2014) and a true experiment (Allred \& Crowley, 2017) reported similar results. The mere recollection of a phone's presence negatively affected ratings of meaningful conversations, whether the phone was active and used or not. Thus, technology appears to impinge, unwittingly, upon relationships.

Technology and relationships. Gergen (2002) noted that technology can be used to create absent presence, where one may be physically present, but mentally absent from their environment. Such a phenomenon is not new. Absent presence has been around as long as daydreaming, and aided in previous centuries by books. The difference is the near infinite nature of the Web; no one arrives at the last page of the Internet. The constantly updating nature of social media, combined with a "fear of missing out" or "FOMO," means these pocketable devices are always ready to transport us from our present moment and social interactions to infinite other spaces (Beyens, Frison, \& Eggermont, 2016; Blackwell, Leaman, Tramposch, Osborne, \& Liss, 2017).

Significant numbers of people do use their phones to absent themselves from their immediate social environments, especially contexts involving children. Radesky et.al., (2014) conducted naturalistic research in fast food restaurants and found that in 40 of 55 caregiver-child groups, caregivers were on their phones, absent, and absorbed to varying degrees. In addition, the study noted that children frequently acted out when their parents were distracted by their devices. Hiniker, Sobel, Suh, Sung, Lee \& Kientz (2015) observed children on playgrounds and saw that $59 \%$ of parents used phones, though most only briefly. When later interviewed about their phone use parents commented that they were present for their child. On the contrary, Hiniker et al., observed 32 playground situations wherein a child tried to get a parent's attention when the parent was on the phone. Eighteen times (58\%) the caregiver did not look up or acknowledge their child. In contrast, caregivers attended to the children $89 \%$ of the time of the time when not using a device. The children offered a different perspective. A survey of 1521 children aged 6-12 found that $62 \%$ described their parents as distracted when they tried to talk to them; cellphones were most often responsible (“Highlights The State of the Kid, 2014," 2014).

Not only can smartphones adversely affect parent-child relationships, they can also interfere with intimate adult relationships, a phenomenon McDaniel and Coyne (2015) called "technoference." Their research found that as technoference increased, rates of depression and relationship conflict also rose, 
while life satisfaction and relationship quality decreased. Further, Roberts and David (2016) describe situations wherein people deliberately use their phones to create distance from their partners. They termed this action phone snubbing phubbing. Phubbing an intimate partner can result in conflict over cell phone use, which harms relationship satisfaction. This, in turn, has been shown to increase depression and decrease life satisfaction (Roberts \& David, 2016).

Finally, a national, natural experiment unfolded in Italy concerning smartphones and relationships. The national telecom expanded $4 \mathrm{G}$ wireless services region by region, moving from North to South. Analyses of large national datasets found that as smartphone capability increased in each region, time spent with friends and subjective well-being simultaneously decreased (Rotondi, Stanca, \& Tomasuolo, 2017).

We have rapidly and universally adopted smartphones and live in a world where technology mediates our interpersonal interactions. We are only beginning to appreciate the social impact of ubiquitous personal technology; however, early research suggests that it may be a socially disruptive force.

\section{Learning: Inherently Social}

Social constructivism. It is widely regarded that learning involves social aspects. Constructivism, a dominant education theory, proposes that students actively create knowledge and understanding as they solve problems and wrestle with new ideas. Building on that concept, social constructivism adds that learning occurs in the context of interacting with others. Learning is forged from social "forms and processes" (Adams, 2006, p. 246) and emerges from dialogue between people, before it is internalized within the person. Not only is learning social, but epistemological work -- that is, "testing what we know," verifying, or discerning "truth"--also depends on social consensus, and not some independent, objective criteria. We view our knowledge to be correct or false depending upon how it aligns with what others say and believe (Heylighen, 1993). Learning, and knowledge, are inherently social (Adams, 2006; Kim, 2001; Powell \& Kalina, 2009; Vygotsky, 1962).

Collaborative learning. Although the preceding comments about social constructivism might be considered somewhat philosophical, they have practical applications in the classroom. Recognizing that learning is social and that knowledge is socially constructed, teachers have sought to harness the power of group work through collaborative learning (CL) in the classroom. Although some use concept of CL differently, escaping, a precise definition, Dillenbourg, an authority on $\mathrm{CL}$, proposed three essential elements. First, the method involves two or more people are involved, which may be a pair of students or hundreds of learners. Second, students learn. They work to complete a task, solve a problem, or work toward a shared learning goal. Third, they engage together. Collaboration, from the Latin "co-labor," implies students work together, though this may be synchronous, or not, face to face, or not, and with frequent contact, or not. As a final element, "co-labor" also suggests group members have equal hierarchical status, though teachers may prescribe roles for 
students to perform different functions within the group (Dillenbourg, 1999). Pedagogically, CL moves from a didactic, teacher-to-student transfer of knowledge to a learning experience marked by cooperation between faculty and students, wherein both are active participants. And, like social constructivism, CL holds that knowledge emerges from and resides in the group, rather than from the individual. Beyond these basic parameters, CL can take many different forms (Dillenbourg, 1999).

In recent years collaborative learning has moved online. One example is the creation of wikis, websites that allow for the collaborative editing of content. The result is a digital product reflecting social and collaborative learning among individuals (Augar, Raitman, \& Zhou, 2004; Roussinos \& Jimoyiannis, 2013; Su \& Beaumont, 2010; Wheeler, Yeomans, \& Wheeler, 2008;). Although much of the research has been on defining and measuring learning vis-a-vis wikis, Pifarre' and Staarman (2011) completed an interesting study that revealed the development of intersubjectivity among primary grade learners involved in learning through a collaborative wiki. Across time, writing and reasoning unfolded that reflected shared perspective taking. The student work reflected "thinking together" as opposed to being the result of individuals working independently.

In contrast to wikis, massive open online courses (MOOCs), are not inherently social or solitary. Studies find that amidst a sea of 1000 students or even 100,000 students taking a course, "islands of collaboration" (Blom, Verma, Li, Skevi, \& Dillenbourg, 2013, p. 2) crop up. Students may be assigned to study groups; they may take initiative to connect with other students via social media, or use sites such as MeetUp to self-organize social learning virtually or physically with other collocated students. Although collaboration may spontaneously develop, it best practices indicates building CL into the design of the course. Thus, CL may occur through required discussion boards or in chat rooms that are built into the learning platform (Yousef, Chatti, Schroeder, \& Wosnitza, 2014; Zheng, Niiya, \& Warschauer, 2015; Zheng, Rosson, Shih, \& Carroll, 2015). CL within MOOC design is viewed to be especially important because the social connection can address one of the MOOC's most significant problems: student retention and persistence (Ferschke, Yang, Tomar, \& Rosé, 2015)

Researchers have extensively studied, researched and assessed, and written about CL (Ashman \& Gillies, 2003; Barkley, Cross, \& Major, 2014; Johnson \& Johnson, 2002). A seminal, often cited study found that teachers are more likely to use facilitative and encouraging verbal interactions with their students when using CL. On the other hand, those same teachers drew upon more authoritarian, impersonal and rigid communication styles when they relied on didactic instruction (Hertz-Lazarowitz \& Shachar, 1990). Further, with CL teachers make more mediated learning responses (paraphrasing students' words, encouraging the group to consider the perspective of one of its members) and offer fewer disciplinary comments. The same research found that the learning groups began to imitate among themselves the facilitative interactions they saw modeled by their teacher (Gillies, 2006). Other research suggests that 
the social component of CL functions to motivate student learning (Järvelä, Volet, \& Järvenoja, 2010). As previously noted, learning is social. CL, in its many forms, and with and without technology, harnesses relationships in the service of learning and the co-creation of knowledge.

Social skills development. The importance of social interaction in education goes beyond learning, social constructivism and CL. Teachers also establish norms of behavior, cultural values, and interaction in a socially productive way. Historically, researchers have referred to this secondary purpose of education as the hidden curriculum (Giroux \& Penna, 1979; Jackson, 1968; Jackson 1990; Wrenn, 1999). Educators note that developing basic social competence is important for student development (Brownlee, et al., 2013; Cartledge \& Milburn, 1978).

Social competence, the social skills requisite for successful interaction, is beneficial for the well-being of youth. A Finnish study of 412 adolescents found that cooperation skills predicted psychological well-being, and reduced levels of disruptiveness and impulsivity (Holopainen, Lappalainen, Junttila, \& Savolainen, 2012). A longitudinal study of a non-clinical sample of 117 children , assessed at age four, observed that poor social competence assessed at age four appeared to set in motion a negative developmental cascade and predicted internalizing and externalizing behaviors at ten and fourteen years of age (Bornstein, Hahn, \& Haynes, 2010). For these reasons, among others, some scholars posited it was incumbent upon schools to create a positive social environment that promoted diversity, cooperation, respect, and connectedness, toward the end of developing social competence in students (Domitrovich, Durlak, Staley, \& Weissberg, 2017).

Social skills are also work skills, though they may assume different names. In an information economy, work is knowledge-based, complex, and cuts across specialized niches. The ability, then, to work together with diverse others to achieve a goal, to manage negative emotions, and to navigate relationships, is a workplace requirements. In work contexts, these interconnected abilities are generally known as soft skills; however, outside the workplace, descriptions may take other forms, such as: emotional competence, cultural competence, social intelligence, and emotional intelligence. Regardless of what, exactly, they may be called, these skills are often found to be lacking and need to be honed if one is to be successful in the workforce (Carter, 2011; Comer, Darling-Hammond, Goleman, Shriver \& Buffett, 2015; Druskat, Mount \& Sala, 2013; Robles, 2012; Ortiz, Region-Sebest, \& MacDermott, 2016; Schulz, 2008).

Learning is social for many reasons. Learning theory, and social constructivism, specifically, supports the position that we learn through our interactions with others. CL puts this into practice. Further, education has other functions beyond learning, to include establishing norms of social behavior, to cultivating social determinants of mental health and wellness, along with fostering the social and emotional skills required to be effective in the information economy. Because of the importance of developing student social skills, cultivating soft 
skills for the workplace and for democracy, and promoting learning as a product of social interaction, effective teachers often use collaborative learning in the classroom (Beckman, 1990; Chickering \& Gamson, 1987; Dewey, 1997; Johnson \& Johnson, 2009; Millis, 2012).

\section{Classrooms: Technology + Collaborative Learning}

The computer is the most remarkable tool that we've ever come up with. It's the equivalent of a bicycle for our minds...

Steve Jobs (as cited in Krainin \& Lawrence, 1990)

Information and communication technology (ICT) is an umbrella term for the electronic tools involved in the transmission or manipulation of information. These electronic tools may include radio and television, but also more recent additions such as computers, tablets, and video conferencing. ICT has proliferated and is embedded into various domains of living. In the 21st century, work has become more mechanized and, recently, computerized. So, too, have our personal lives have followed suit. Similarly, ICT has moved from the fringes of the classroom toward the center (Bulman \& Fairlie, 2016; Nickerson \& Zodhiates, 2013), and from prophetic vision to realization (Thornburg, 1999).

ICT in education has evolved. Increasingly the technology of education is a computer or tablet, while the educational process involves collaborative learning. This narrowed application, sometimes referred to as computersupported collaborative learning (CSCL), has created a growing body of research (Kirschner \& Erkens, 2013; Ludvigsen \& Armseth, 2017).

One study from Singapore examined students' views of collaborative learning (CL) and self-directed learning (SDL) with and without technology. The researchers used a 26 item self-report measure that assessed student perception about their active involvement in learning. Using survey responses from 500 secondary school students they found that students who did well with CL and SDL in face-to-face settings also viewed themselves to be effective learners when ICT was added. This finding suggested to the researchers that strengthening students' effectiveness in SDL and CL in face to face contexts would also improve their perception of their effectiveness in technology-mediated learning (Lee, Tsai, Chai, \& Koh, 2014)

Large meta-analyses have found significant benefits to K-12 learning when technology supports but not replace instruction. Sung, Chang, and Liu (2016) reviewed 110 articles published in peer-reviewed journals between 1993 and 2013. They observed that using mobile devices aided learning more than did desktop computers or having no ICT. Further, inquiry-oriented learning with technology proved more effective than trying to embed technology use within lecture, cooperative learning, or self-directed learning. Short and medium term interventions were more effective than longer term learning with technology. Finally, the authors concluded that technology by itself was insufficient to promote learning. Smart instructional design must leverage specific, key benefits of technology, such as instant feedback or communication across 
groups, in order to make a difference in student learning. A second, secondorder meta-analysis summarized 40 years of research on ICT and student achievement in face-to-face learning compared to classrooms without instructional ICT. This review of 25 meta-analyses, which included 1055 primary studies and over 100,000 subjects, found that technology improved learning, and that the effect was more evident when the ICT supported the teacher, rather than supplanted the teacher, (i.e., "support for instruction" versus "direct instruction"). Technology "serves at the pleasure of instructional design, pedagogical approaches and teacher practices" (Tamim, Bernard, Borokhovski, Abrami, \& Schmid, 2011, p. 17). So, to summarize, does technology aid learning?" After surveying four decades of data, Tamim et al. (2011) proposed a strong and conclusive, "yes." Looking forward, the researchers suggested moving from binary exploration (technology or not) toward more nuanced questions perhaps addressing specific software or activities.

Learning is social. Technology enhances learning. Technology may impede social interactions and presence. It is not known for certain what effect technology has upon group interactions in a learning context. However, based upon this review of the literature, we generalize and hypothesize that technology will impede collaborative learning. This research may address that question and contribute to a more nuanced understanding, such as identified by Tamim et al. (2011), concerning the role of technology in education.

\section{Method}

In order to assess the effect of technology on collaborative learning, the researchers devised a two group, randomized, post-test only experiment. Research assistants who collected data and study participants had no knowledge of the research question. Assistants collected the data during the second half of 2017.The data was collected in the second half of 2017.

\section{Participants and site}

Participants in this project included the principal investigator (PI), who was involved in study design and execution, three primary grade teachers, six research assistants, and three primary grades classes comprising 71 students. The research assistants were senior undergraduate students from an upper division class in human development. Their participation earned extra credit for that course. The teachers work at the university-affiliated lab school and served as co-investigators. The children studied derived from first, fourth and sixth grades at the same lab school, and were selected as a convenience sample. Geographically and culturally the population at the lab school loosely reflected the county in which the students resided, that was, 92\% Caucasian and middle class with a median household income of $\$ 43,000$, (United States Bureau Quick Facts, 2017). Culturally, the sample was from a southern Appalachian community of 50,000 to 100,000 people. This experiment explored group interaction as the unit of analysis, however, not individual students. Of note, the project took place in the last quarter of the school year. This is a school 
environment wherein students generally remained with the same classmates year after year. These factors, combined, suggested the students were very familiar with one another.

\section{Procedure}

The project required preliminary effort. First, the PI obtained the approval of the East Tennessee State University Institutional Review Board (IRB) for the research protocol. Parents and children who enroll in the laboratory school understand it is a venue for educational research and consent to being involved in educational research employing established practices in the classroom environment as a precondition to enrollment. A checklist for effective collaborative learning, the Collaborative Learning Checklist (CLC) (Appendix A) was created by the research team after a review of the literature failed to identify an acceptable measure of group function. The CLC measured (a) eye contact, (b) fulfillment of roles, (c) productivity, (d) staying on task, and (e) verbal interactions. The form had face validity among the educators on the research team, but there was no further effort at establishing construct validity. The research team decided instrument testing was beyond the scope of the research project. The form also included space for observers to jot down qualitative observations of group interactions.

The PI then recruited and trained six research assistants (RA) to use the CLC. Following two training sessions, the research assistants applied the CLC to three practice vignettes. Interrater reliability scoring the practice vignettes scored over $90 \%$, which satisfied predetermined criteria.

The teachers designed two analogous CL activities for their classes, both consistent with state standards for content. One activity involved the use of a single iPad tablet shared among group members, while the other analogous task required students to work together from non-electronic sources, such as classroom textbooks, informational texts, and other print sources.

As the research got underway, teachers (not blinded) then randomly assigned the students in their classes into collaborative learning groups of three or four students to complete a project with technology (experimental) or without (control). The collaborative learning activity was different for each grade observed and consistent with the learning needs prescribed by state standards. Each class, then, contained six learning groups, blinded as to the purpose of the study.

Blinded RAs, trained in using the CLC but uninformed about the research purpose, were situated around the classroom. Researchers assumed that the presence of observers did not affect the dynamics because it was a laboratory school, and the students were accustomed to having observers. The RAs used the CLC to measure the social dynamics of student learning groups. The collaborative learning exercise lasted approximately 15 minutes. After this time, the PI collected the scored CLCs for analysis, entered into SPSS, and ran $t$-tests on the five different indicators of cooperative learning were conducted. 


\section{Results}

Observers monitored 18 groups, each consisting of three or four students. Of these groups, nine received technology (tablet) to complete a learning task while the remaining nine groups were asked to do so without the use of technology. During the task, observers scored the groups on five variables: (a) eye contact, (b) fulfillment of roles, (c) productivity, (d) staying on task, and (e) verbal interactions.

SPSS Statistics version 23.0 conducted the statistical analyses of these data. As we compared continuous independent variables among two distinct groups, an independent samples $t$-test served to compare means. The eye contact variable showed no significant difference between the two groups, $t(16)=1.35 ; p=0.182$. The productivity variable showed no significant difference between the two groups, $t(16)=1.101 ; p=0.287$. The staying on task variable showed no significant difference between the two groups, $t(16)=1.525 ; p=0.147$. The verbal interactions variable showed no significant difference between the two groups, $t(16)=-0.658$; $p=0.520$. The sample means are displayed in Figure 1 below, which shows that groups utilizing technology to complete the assigned task scored similarly to those groups who did not utilize technology in each of the four aforementioned variables (eye contact: for those groups utilizing technology, $M=1.8889$, $\mathrm{SD}=1.05409$; for those groups not utilizing technology, $\mathrm{M}=1.222, \mathrm{SD}=0.97183$, productivity: for those groups utilizing technology, $\mathrm{M}=2.0000, \mathrm{SD}=1.73205$; for those groups not utilizing technology, $\mathrm{M}=1.1111, \mathrm{SD}=1.69148$, staying on task: for those groups utilizing technology, $\mathrm{M}=2.8889, \mathrm{SD}=2.26078$; for those groups not utilizing technology, $\mathrm{M}=1.3333, \mathrm{SD}=2.06155$, and verbal interactions: for those groups utilizing technology, $\mathrm{M}=0.6667, \mathrm{SD}=1.11803$; for those groups not utilizing technology, $\mathrm{M}=1.1111, \mathrm{SD}=1.69148$.

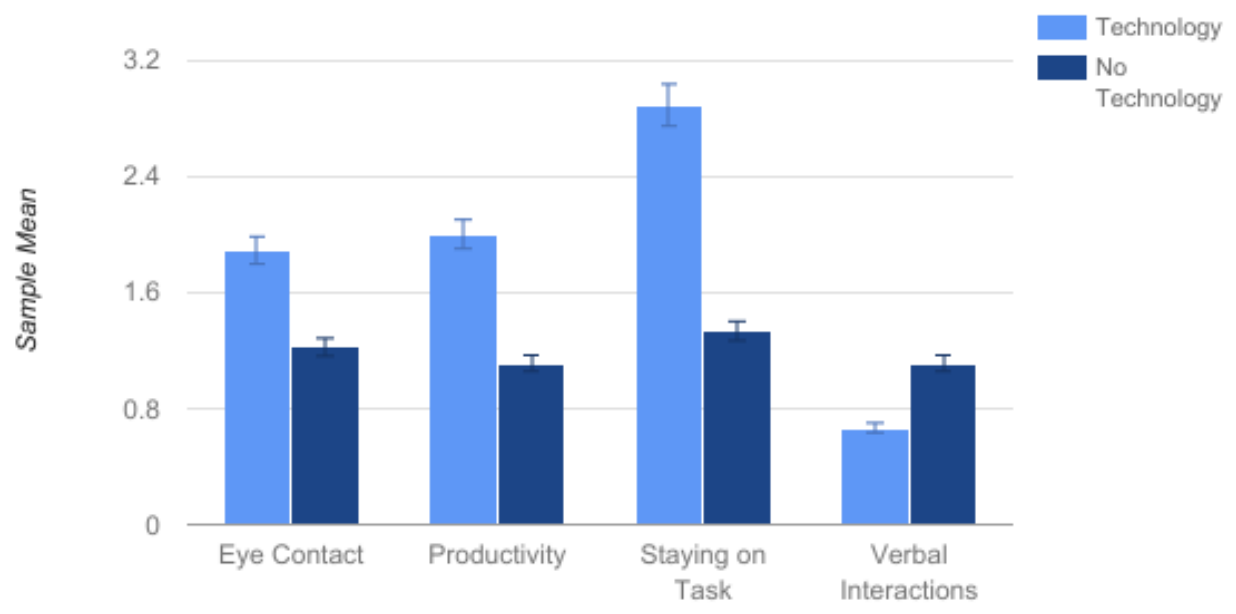

Figure 1. Sample means of four variables. 
Alternately, analyses of the fulfillment of roles variable did show a significant difference between the two groups, $t(16)=2,874 ; p=0.011$. The sample means are displayed in Figure 2, which shows that groups utilizing technology to complete the assigned task scored significantly lower on fulfilling their assigned task as compared to those groups who did not utilize technology (for the groups utilizing technology, $\mathrm{M}=1,000, \mathrm{SD}=0.86603$; for the groups not utilizing technology, $\mathrm{M}=9, \mathrm{SD}=0.1111$ ).

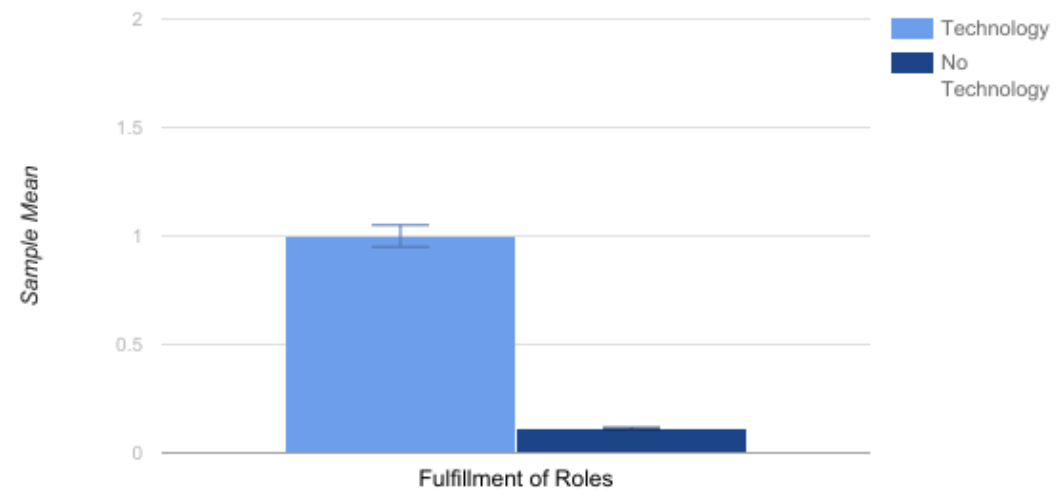

Figure 2. Sample mean of one variable.

\section{Discussion}

Several important secular forces intersect in this study. First, technology is now ubiquitous in the US (Pew Center for Research, 2017). Second, previous research with adult subjects has found that technology influenced social interactions (Engelberg \& Sjöberg, 2004; Misra, et al., 2016; Radesky, et al, 2014; Roberts \& David, 2016). Third, whether it reflects a social constructivist orientation to learning, a hidden curriculum, or a more explicit agenda to help students develop the skills required to work in teams, classrooms frequently promote social interaction and collaborative learning (Adams, 2006; Kim, 2001; Powell \& Kalina, 2009; Vygotsky, 1962. Finally, teachers are encouraged to employ technology in the classroom (Zhang, Yang, Chang, \& Chang, 2016); however, studies that explore the influence of technology on collaborative classroom learning appear non-existent. We believe this study represents an important contribution to our understanding of classroom dynamics and whether technology affects collaborative learning interactions.

Contrary to our hypothesis, we found scant evidence to support the premise that technology affected CL interactions more than non-electronic learning resources, such as worksheets or books, did. Of the five elements assessed by the CLC, only "roles fulfilled" was diminished in a statistically significant way. However, 
it is also worth noting that there was also a strong contrast between the two groups on the measure of "staying on task." The technology group was on task at a mean level of 2.89, while the non-technology group was on task at a mean level of 1.33 (note lower is more focused). This difference was significant at a 2 tailed level of .147. The small number of groups (nine with technology and nine without) required a large difference between mean scores to rule out the the observed difference being due to chance.

The brief qualitative component of the CLC offers some possible insight into why students were less likely to fulfill their group roles. Observers of the groups using iPads recorded a child in one group exclaiming, "look how many games are on this!" Another technology group appeared distracted and not visiting the prescribed websites at first. This suggests that it may be important to narrowly restrict the ICT to only the purposes intended. This is especially true, considering how the prefrontal cortex in children is not well developed, executive function is not mature, and impulse control is limited (Aron, Robbins, \& Poldrack, 2014; Zelazo \& Muller, 2010). Young children are more easily distracted and ICT may pose a greater distraction risk compared to other nontechnology resources. This may affect students completing their role and staying on task.

Although some research finds negative effects from technology on our personal lives and relationships (Engelberg \& Sjoberg, 2004; Gergen, 2002; Radesky, et al, 2014; Radesky, et al, 2015; Roberts \& David, 2016; Turkle, 2011), this research aligned with the work of Zilberstein, who found such hand-wringing misplaced (Zilberstein, 2016). Tablets used in collaborative learning did not greatly affect the social processes measured by the CLC. The two exceptions were students fulfilling roles and staying on task, though the latter was not statistically significant. This research suggests that students will benefit if educators limit non-instructional material that can be accessed on ICT. This is likely a case where "less is more," at least concerning focus. If they keep digital distractions to a minimum, our research suggests educators should have little concern about the effect of ICT on group processes.

\section{Limitations}

A few limitations were inherent in the design of this research. The first concerns the CLC. Strijbos and Fischer (2007) summarized the state of research methods used to study collaborative learning. For example, there are assessments for knowledge acquisition and knowledge convergence within the group (Weinberger, Stegmann, \& Fischer, 2007). One study even considered the shared use of a mouse, keyboard, or monitor as an indicator of collaboration (Hwang \& Karnofsky, 2005).

From our review it appeared that research tended to neglect social processes in CL; Kreijs, Kirschner, and Jochems (2003) suggested that educators tend to take social interaction for granted. Our research team decided none of the existing tools were appropriate for what they attempted to measure: social processes and role completion. Consequently, the tool we created to collect data on 
collaborative learning processes was a simple, but unproven, checklist. A validated and more widely recognized instrument for effective collaborative processes would bolster the quality of this research and other investigations. We recommend the creation and validation of such a tool for future research.

Second, because the unit of analysis was learning groups, we had a sample size of only nine for each condition. This negatively affected our statistical power and made it more difficult to reject the null hypothesis in our analysis. To be sure, there were observable differences; we were mere unable to claim confidently that the differences were not due to chance.

Future research might seek to validate an instrument to measure the social components of collaborative learning. Further, researchers may wish to recruit a greater number of participants, increase statistical power, and decrease the risk of a Type II error. This research occured in an authentic classroom environment. More controls could be implemented if students were out of their classes and placed in an observation room, though that would negatively affect ecological validity

\section{References}

Adams, P. (2006). Exploring social constructivism: Theories and practicalities. Education, 34(3), 243-257. doi:10.1080/03004270600898893

Aron, A. R., Robbins, T. W., \& Poldrack, R. A. (2014). Inhibition and the right inferior frontal cortex: One decade on. Trends in Cognitive Sciences, 18(4), 177-185. doi:10.1016/j.tics.2013.12.003

Alred, R. J., \& Crowley, J. P. (2017). The "mere presence" hypothesis: Investigating the nonverbal effects of cell-phone presence on conversation satisfaction. CommunicationStudies, 68(1), 22-36. doi:10.1080/10510974.2016.1241292

Ashman, A., \& Gillies, R. (Eds.). (2003). Cooperative learning: The social and intellectual outcomes of learning in groups. Abingdon, UK: Routledge.

Augar, N., Raitman, R., \& Zhou, W. (2004, January). Teaching and learning online with wikis. In Beyond the comfort zone: Proceedings of the 21st ASCILITE Conference, Perth, 5-8 December (pp. 95-104). ASCILITE.

Bandura, A., Ross, D., \& Ross, S. A. (1963). Imitation of film-mediated aggressive models. The Journal of Abnormal and Social Psychology, 66(1), 3. doi:10.1037/h0048687

Barkley, E. F., Cross, K. P., \& Major, C. H. (2014). Collaborative learning techniques: A handbook for college faculty. Hoboken, New Jersey: John Wiley \& Sons.

Beckman, M. (1990). Collaborative learning: Preparation for the workplace and democracy?. College Teaching, 38(4), 128-133. doi:10.1080/87567555.1990.10532425

Beyens, I., Frison, E., \& Eggermont, S. (2016). "I don't want to miss a thing": Adolescents' fear of missing out and its relationship to adolescents' social needs, Facebook use, and Facebook related stress. Computers in Human Behavior, 64, 1-8. doi:10.1016/j.chb.2016.05.083

Blackwell, D., Leaman, C., Tramposch, R., Osborne, C., \& Liss, M. (2017). Extraversion, neuroticism, attachment style and fear of missing out as predictors of social media use and addiction. Personality and Individual Differences, 116, 69-72. doi:10.1016/j.paid.2017.04.039 
Blom, J., Verma, H., Li, N., Skevi, A., \& Dillenbourg, P. (2013). MOOCs are more social than you believe (No. EPFL-WORKING-190099). eLearning Papers.

Bornstein, M. H., Hahn, C. S., \& Haynes, O. M. (2010). Social competence, externalizing, and internalizing behavioral adjustment from early childhood through early adolescence: Developmental cascades. Development and psychopathology, 22(04), 717-735. doi:10.1017/S0954579410000416

Brownlee, K., Rawana, J., Franks, J., Harper, J., Bajwa, J., O’Brien, E., \& Clarkson, A. (2013). A systematic review of strengths and resilience outcome literature relevant to children and adolescents. Child and Adolescent Social Work Journal, 30(5), 435-459. doi:10.1007/s10560-013-0301-9

Bulman, G., \& Fairlie, R. W. (2016). Technology and education: Computers, software, and the Internet (No. w22237). National Bureau of Economic Research.

Carter, L. (2011). Ideas for adding soft skills education to service learning and capstone courses for computer science students. In Proceedings of the 42nd ACM technical symposium on Computer science education (pp. 517-522). ACM. doi:10.1145/1953163.1953312

Cartledge, G., \& Milburn, J. F. (1978). The case for teaching social skills in the classroom: A review. Review of Educational Research, 48(1), 133-156. doi:10.3102/00346543048001133

Chickering, A. W., \& Gamson, Z. F. (1987). Seven principles for good practice in undergraduate education. AAHE bulletin, 3, 7 .

Comer, J. P., Darling-Hammond, L., Goleman, D., Shriver, T. P., \& Buffett, J. (2015). Handbook of Social and Emotional Learning: Research and Practice. J. A. Durlak, C. E. Domitrovich, R. P. Weissberg, \& T. P. Gullotta (Eds.). New York City: Guilford Publications.

Dewey, J. (1997). How we think. North Chelmsford, MA: Courier Corporation.

Dillenbourg, P. (1999). What do you mean by collaborative learning. CollaborativeLearning: Cognitive and Computational Approaches, 1, 1-15.

Druskat, V. U., Mount, G., \& Sala, F. (2013). Linking emotional intelligence and performance at work: Current research evidence with individuals and groups. New York City: Psychology Press.

Emanuel, R., Bell, R., Cotton, C., Craig, J., Drummond, D., Gibson, S., ... \& Lewis, J. (2015). The truth about smartphone addiction. College Student Journal, 49(2), 291299.

Engelberg, E., \& Sjöberg, L. (2004). Internet use, social skills, and adjustment. CyberPsychology \& Behavior, 7(1), 41-47. doi:10.1089/109493104322820101

Ferguson, C. J. (2015). Do angry birds make for angry children? A meta-analysis of video game influences on children's and adolescents' aggression, mental health, prosocial behavior, and academic performance. Perspectives on Psychological Science, 10(5), 646-666. doi:10.1177/1745691615592234

Ferschke, O., Yang, D., Tomar, G., \& Rosé, C. P. (2015, June). Positive impact of collaborative chat participation in an edx mooc. In International Conference on Artificial Intelligence in Education (pp. 115-124). Cham, Switzerland: Springer International Publishing. doi:10.1007/978-3-319-19773-9_12

FitzPatrick, S., Twohig, M., \& Morgan, M. (2014). Priorities for primary education? From subjects to life-skills and children's social and emotional development. Irish Educational Studies, 33(3), 269-286. doi:10.1080/03323315.2014.923183

Gergen, K. (2002). The challenge of absent presence. In J.E. Katz and M. Aarkhus (Eds.) Perpetual Contact: Mobile communication, private talk, public performance. (pp. 227241). New York: Cambridge University Press.

Gillies, R. M. (2006). Teachers' and students' verbal behaviours during cooperative and small group learning. British Journal of Educational Psychology, 76(2), 271-287. doi:10.1348/000709905X52337 
Giroux, H. A., \& Penna, A. N. (1979). Social education in the classroom: The dynamics of the hidden curriculum. Theory \& Research in Social Education, 7(1), 21-42. doi:10.1080/00933104.1979.10506048

Hertz-Lazarowitz, R., \& Shachar, H. (1990). Teachers' verbal behaviour in cooperative and whole-class instruction. Cooperative Learning: Theory and Research, 77-94.

Heylighen, F. (1993). Epistemology, Introduction, on Principia Cybernetica Web site at http:/ / pespmc1.vub. ac. be. EPISTEMI. html.

Highlights The State of the Kid, 2014 (2014). Retrieved from: https://cdn.highlights.com/hfc/highlights/state-of-the-kid/HighlightsSOTK14.pdf

Hiniker, A., Sobel, K., Suh, H., Sung, Y. C., Lee, C. P., \& Kientz, J. A. (2015, April). Texting while parenting: How adults use mobile phones while caring for children at the playground. In Proceedings of the 33rd Annual ACM Conference on Human Factors in Computing Systems (pp. 727-736). ACM. doi:10.1145/2702123.2702199

Holopainen, L., Lappalainen, K., Junttila, N., \& Savolainen, H. (2012). The role of social competence in the psychology well-being of adolescents in secondary education. Scandinavian Journal of Educational Research, 56(2), 199-212. doi: $10.1080 / 00313831.2011 .581683$

Hwang, S., \& Karnofsky, P. (2015). Defining, measuring, and improving collaboration through evaluating the Cornell Library Collaborative Learning Computer Laboratory. Unpubl. Cornell Cl. Rep. Retrieved from: http://www.cs.cornell.edu/dis/cl3/evaluation/info440fa05.pdf

Jackson, P. W. (1968). Life in Classrooms. New York: Holt, Rinehart and Winston.

Jackson, P. W. (1990). Life in classrooms. New York: Teachers College Press.

Järvelä, S., Volet, S., \& Järvenoja, H. (2010). Research on motivation in collaborative learning: Moving beyond the cognitive-situative divide and combining individual and social processes. Educational Psychologist, 45(1), 15-27. doi: $10.1080 / 0046152090343353$

Johnson, D. W., \& Johnson, R. T. (2002). Learning together and alone: Overview and meta analysis. Asia Pacific Journal of Education, 22(1), 95-105. doi:10.1080/0218879020220110

Johnson, D. W., \& Johnson, R. T. (2009). An educational psychology success story: Social interdependence theory and cooperative learning. Educational Researcher, 38(5), 365-379. doi:10.3102/0013189X09339057

Kim, B. (2001). Social constructivism. Emerging Perspectives on Learning, Teaching, and Technology, 1(1), 16.

Kirschner, P. A., \& Erkens, G. (2013). Toward a framework for CSCL research. Educational Psychologist, 48(1), 1-8. doi:10.1080/00461520.2012.750227

Krainin, J., \& Lawrence, M. R. (Eds.). (1990). Memory \& Imagination: New Pathways to the Library of Congress. Encyclopedia Britannica Educational Corporation.

Kranzberg, M. (1986). Technology and History:" Kranzberg's Laws". Technology and culture, 27(3), 544-560.

Kreijns, K., Kirschner, P. A., \& Jochems, W. (2003). Identifying the pitfalls for social interaction in computer-supported collaborative learning environments: a review of the research. Computers in human behavior, 19(3), 335-353. doi:10.1016/S0747-5632(02)00057-2

Kuss, D. J., \& Lopez-Fernandez, O. (2016). Internet addiction and problematic Internet use: A systematic review of clinical research. World journal of psychiatry, 6(1),143. doi:10.5498/wjp.v6.i1.143

Lee, K., Tsai, P. S., Chai, C. S., \& Koh, J. H. L. (2014). Students' perceptions of self directed learning and collaborative learning with and without technology. Journal of Computer Assisted Learning, 30(5), 425-437. doi:10.1111/jcal.12055 
Liang, L., Zhou, D., Yuan, C., Shao, A., \& Bian, Y. (2016). Gender differences in the relationship between internet addiction and depression: A cross-lagged study in Chinese adolescents. Computers in Human Behavior, 63, 463-470. doi:10.1016/j.chb.2016.04.043.

Ludvigsen, S., \& Arnseth, H. C. (2017). Computer-Supported Collaborative Learning. In Technology enhanced learning (pp. 47-58). Cham, Switzerland: Springer International Publishing.

Malak, M. Z., \& Khalifeh, A. H. (2018). Anxiety and depression among school students in Jordan: Prevalence, risk factors, and predictors. Perspectives in psychiatric care, 54(2), 242-250. doi:10.1111/ppc.12229

McDaniel, B. T., \& Coyne, S. M. (2016). "Technoference": The interference of technology in couple relationships and implications for women's personal and relational well-being. Psychology of Popular Media Culture, 5(1), 85. doi:10.1037/ppm0000065

Millis, B. J. (2012). Why faculty should adopt cooperative learning approaches. Cooperative Learning in Higher Education: Across the Disciplines, Across the Academy, 1.

Misra, S., Cheng, L., Genevie, J., \& Yuan, M. (2016). The iPhone effect: The quality of inperson social interactions in the presence of mobile devices. Environment and Behavior, 48(2), 275-298.

Nickerson, R. S., \& Zodhiates, P. P. (Eds.). (2013). Technology in education: Looking toward 2020. New York City: Routledge.

Ortiz, L. A., Region-Sebest, M., \& MacDermott, C. (2016). Employer perceptions of oral communication competencies most valued in new hires as a factor in company success. Business and Professional Communication Quarterly, 79 (3), 317-330. doi: $10.1177 / 2329490615624108$

Pew Research Center (2015). Technology device ownership: 2015. Retrieved from: http:/ / www.pewinternet.org/2015/10/29/technology-device-ownership-2015/

Pew Research Center (2018). Record shares of Americans now own smartphones, have home broadband Retrieved from: http://www.pewresearch.org/facttank/2018/01/12/evolution-of-technology/

Pifarré, M., \& Staarman, J. K. (2011). Wiki-supported collaborative learning in primary education: How a dialogic space is created for thinking together. International Journal of Computer-Supported Collaborative Learning, 6(2), 187. 10.1007/s11412011-9116-x

Powell, K. C., \& Kalina, C. J. (2009). Cognitive and social constructivism: Developing tools for an effective classroom. Education, 130(2), 241.

Przybylski, A. K., \& Weinstein, N. (2013). Can you connect with me now? How the presence of mobile communication technology influences face-to-face conversation quality. Journal of Social and Personal Relationships, 30(3), 237-246. doi: $10.1177 / 0265407512453827$

Radesky, J. S., Kistin, C. J., Zuckerman, B., Nitzberg, K, Gross, J., Kaplan-Sanoff, M., Augustyn M., \& Silverstein, M. (2014). Patterns of mobile device use by caregivers and children during meals in fast food restaurants. Pediatrics,133(4), 843-849.

Radesky, J. S., Schumacher, J., \& Zuckerman, B. (2015). Mobile and interactive media use by young children: The good, the bad, and the unknown. Pediatrics, 135(1), 1-3. 10.1542/ peds.2014-2251

Roberts, J. A., \& David, M. E. (2016). My life has become a major distraction from my cell phone: Partner phubbing and relationship satisfaction among romantic partners. Computers in Human Behavior, 54, 134-141. 10.1016/j.chb.2015.07.058 
Robles, M. M. (2012). Executive perceptions of the top 10 soft skills needed in today's workplace. Business Communication Quarterly, 75(4), 453-465. doi: $10.1177 / 1080569912460400$

Rotondi, V., Stanca, L., \& Tomasuolo, M. (2017). Connecting alone: Smartphone use, quality of social interactions and well-being. Journal of Economic Psychology, 63, 17-26.

Roussinos, D., \& Jimoyiannis, A. (2013). Blended collaborative learning through a wikibased project: A case study on students' perceptions. In A. Cartelli, Fostering 21st century digital literacy and technical competency (pp. 130-145). Hershey, PA: IGI Global.

Sapacz, M., Rockman, G., \& Clark, J. (2016). Are we addicted to our cell phones. Computers in Human Behavior, 57, 153-159. doi:10.1016/j.chb.2015.12.004

Schulz, B. (2008). The importance of soft skills: Education beyond academic knowledge. Nawa: Journal of Language \& Communication, 2(1), 146-154.

Strijbos, J. W., \& Fischer, F. (2007). Methodological challenges for collaborative learning research. Learning and Instruction, 17(4), 389-393. doi:https://doi.org/10.1016/j.learninstruc.2007.03.004

Su, F., \& Beaumont, C. (2010). Evaluating the use of a wiki for collaborative learning. Innovations in Education and Teaching International, 47(4), 417-431. doi:10.1080/14703297.2010.518428

Sung, Y. T., Chang, K. E., \& Liu, T. C. (2016). The effects of integrating mobile devices with teaching and learning on students' learning performance: A meta-analysis and research synthesis. Computers $\mathcal{E}$ Education, 94, 252-275. doi:10.1016/j.compedu.2015.11.008

Tamim, R. M., Bernard, R. M., Borokhovski, E., Abrami, P. C., \& Schmid, R. F. (2011). What forty years of research says about the impact of technology on learning: A second-order meta-analysis and validation study. Review of Educational research, 81(1), 4-28. doi: 10.3102/0034654310393361

Thornburg, D. D. (1999, December). Technology in K-12 education: Envisioning a new future. In Proceedings, Forum on Technology in Education: Envisioning the Future, Washington, DC. Retrieved from http:// files.eric.ed.gov/fulltext/ED452843.pdf

Turkle, S. (2011). Alone together: Why we expect more from technology and less from each other. New York: Basic Books

United States Census Bureau (2017) Quick facts: Washington County. Retrieved from https://www.census.gov/quickfacts/table/SBO001212/47179

Vygotsky, L. S. (1962). Thought and language, Cambridge, MA: MIT Press

Weinberger, A., Stegmann, K., \& Fischer, F. (2007). Knowledge convergence in collaborative learning: Concepts and assessment. Learning and Instruction, 17(4), 416-426. doi:10.1016/j.learninstruc.2007.03.007

Wheeler, S., Yeomans, P., \& Wheeler, D. (2008). The good, the bad and the wiki: Evaluating student generated content for collaborative learning. British Journal of Educational Technology, 39(6), 987-995. doi:10.1111/j.1467-8535.2007.00799.x

Wren, D. J. (1999). School culture: Exploring the hidden curriculum. Adolescence, 34(135), 593.

Yayan, E. H., Arikan, D., Saban, F., Gürarslan Baş, N., \& Özel Özcan, Ö. (2017). Examination of the correlation between Internet addiction and social phobia in adolescents. Western Journal of Nursing Research,39(9), 1240-1254. doi: $10.1177 / 0193945916665820$

Yousef, A. M. F., Chatti, M. A., Schroeder, U., \& Wosnitza, M. (2014, July). What drives a successful MOOC: An empirical examination of criteria to assure design quality of MOOCs. In Advanced Learning Technologies (ICALT), 2014 IEEE 14th International Conference on (pp. 44-48), Athens, Greece. doi: 10.1109/ICALT.2014.23 
Zelazo, P. D., \& Mueller, U. (2010). Executive function in typical and atypical development. The Wiley-Blackwell handbook of childhood cognitive development, (Second edition), (pp. 574-603) Hoboken, NJ: Wiley.

Zhang, J., Yang, J., Chang, M., \& Chang, T. (Eds.). (2016). ICT in Education in Global Context: The Best Practices in K-12 Schools. Springer. 10.1007/978-981-10-0373-8

Zheng, B., Niiya, M., \& Warschauer, M. (2015). Wikis and collaborative learning in higher education. Technology, Pedagogy and Education, 24(3), 357-374. doi:http:/ / dx.doi.org/10.1080/1475939X.2014.948041

Zheng, S., Rosson, M. B., Shih, P. C., \& Carroll, J. M. (2015, March). Designing MOOCs as interactive places for collaborative learning. In Proceedings of the Second (2015) ACM Conference on Learning@ Scale (pp. 343-346). Vancouver, CA. doi:10.1145/2724660.2728689

Zilberstein, K. (2015). Technology, relationships and culture: Clinical and theoretical implications. Clinical Social Work Journal, 43(2), 151-158. doi:http://dx.doi.org/10.1007/s10615-013-0461-2 